\title{
THE INFLUENCE OF GRINDING CONDITIONS ON THE DISTRIBUTION OF RESIDUAL STRESS IN THE SURFACE LAYER OF 17CRNI6-6 STEEL AFTER CARBURIZING
}

\author{
Jacek Sawicki', Bogdan Kruszyński², Ryszard Wójcik² \\ 1 Institute of Materials Science and Engineering Faculty of Mechanical Engineering, Lodz University of \\ Technology, 1/15 Stefanowskiego Str., 90-924 Łódź, Poland, e-mail: jacek.sawicki@p.lodz.pl \\ 2 Institute of Machine Tools and Production Engineering, Faculty of Mechanical Engineering, Lodz University \\ of Technology, 1/15 Stefanowskiego Str., 90-924 Łódź, Poland, e-mail: bogdan.kruszynski@p.lodz.pl, ryszard. \\ wojcik@p.lodz.pl
}

Received: 2016.11 .28

Accepted: 2017.02.07

Published: 2017.06.01

\begin{abstract}
This paper presents the results of a study aimed at determining the residual stress which results from developing the surface layer by low-pressure and conventional carburizing and grinding of $17 \mathrm{CrNi6}-6$ steel. A synergistic effect of thermochemical and abrasive treatment was examined on ring samples used to study residual stress by Davidenkov's method. Samples were subjected to vacuum carburizing and conventional carburizing, which was followed by grinding with a $38 \mathrm{~A} 60 \mathrm{~K} 8 \mathrm{~V}$ aloxite grinding wheel and a CBN grinding wheel - RNB80/63B75V. The following cutting fluids were used during the grinding process: oil emulsion $5 \%$, supply rate ca. $20 \mathrm{l} / \mathrm{min}$, Micro5000 oil supplied at the minimum quantity lubrication (MQL) of ca. $25 \mathrm{ml} / \mathrm{h}$, dry machining. The study determined the effect of the type of grinding wheel and the cooling and lubricating agent on the distribution of residual stress in the surface layer. The best effects of grinding with respect to the residual stress were achieved with flood cooling with oil emulsion and grinding with a CBN grinding wheel.
\end{abstract}

Keywords: synergism, residual stress, carburizing, grinding, cutting fluids.

\section{INTRODUCTION}

There are a number of industrial applications for both these solutions and the issues that arose from their implementation and propagation. The most important of them is to shape the surface layer in order to ensure high contact fatigue and bending fatigue strength of thus produced items. Both these properties depend both on the structure of the surface layers being hardened and on the final distribution of residual stress. There is a need to consider the issues jointly and in an interrelated manner as the transformation of the stress during the process of forming the surface layer includes all the technological processes and it is not a simple sum of the unit processes.
Large-batch industrial process of surface engineering are being constantly modified with the aim of their constant technological, economic and ecological improvement $[7,8,15,18]$. Currently, two innovative solutions in this regard undoubtedly make a great technological revolution. These are: compact low-pressure carburizing which consists in quenching in inert gases (nitrogen or helium) at high pressure $[13,17]$ and use of new generation grinding wheels - with grains of regular boron nitride and with different cutting fluids $[3,11,16]$.

Low-pressure carburizing is better than conventional carburizing in regard to its efficiency; it also has certain other advantages: no internal oxidation, higher uniformity of layers produced in the process, energy efficiency and environmen- 
tal friendliness $[4,6,9,14]$. Unfortunately, material removal processing may result in deterioration of beneficial properties of the surface layer obtained by modern methods of thermochemical treatment, especially in high-performance treatment methods $[1,2,5,10,12,19,20]$.

\section{METHODOLOGY AND CONDITIONS OF THE EXPERIMENT}

The aim of the study was to verify the possibility of achieving a synergistic effect for the usage properties of an item by applying modern processes of thermochemical treatment and material removal treatment. The experiment regarding thermochemical treatment focused on the process of low-pressure and conventional carburizing, whereas for material removal - on grinding with different abrasive devices (grinding wheels with grains of microcrystalline sintered corundum and CBN) and different cooling and lubricating agents.

Samples of $17 \mathrm{CrNi6}-6$ steel were made as ring samples with the dimensions: external diameter $\varnothing 45 \mathrm{~mm}$, internal diameter $\varnothing 38 \mathrm{~mm}$ and width: 6 $\mathrm{mm}$. After the shaping pre-treatment, the samples were annealed in a vacuum furnace at the temperature of $823 \mathrm{~K}$ for 2 hours in order to remove stresses resulting from the mechanical treatment. After annealing, samples were cooled down together with the furnace and subsequently given the thermochemical treatment of carburizing (Table 1). The parameters of the carburizing process were selected such as to achieve the effective case depth of about $0.6 \mathrm{~mm}$ for the $0.40 \% \mathrm{C}$ criterion.

Samples following the thermochemical treatment were given material-removal treatment in order to give the final shape to the surface layer. Plunge grinding of the external cylindrical surfaces was done with a $38 \mathrm{~A} 60 \mathrm{~K} 8 \mathrm{~V}$ and $\mathrm{CBN}-$ RNB80/63B75V aloxite grinding wheels; trials were conducted for sharp grinding wheels at the following parameters: grinding speed (constant), $v_{s}=30 \mathrm{~m} / \mathrm{s}$, grinding depth: $0.025 \mathrm{~mm}$. The following cutting fluids were used in the grinding process: oil emulsion $5 \%$, supply rate ca. $201 / \mathrm{min}$, Micro5000 oil supplied at the minimum quantity lubrication (MQL) of ca. $25 \mathrm{ml} / \mathrm{h}$, dry machining.

Residual stress for ring samples was measured by Davidenkov's methods at a measuring

Table 1. Parameters of the thermochemical treatment of $17 \mathrm{CrNi6}-6$ steel

\begin{tabular}{|c|c|c|c|}
\hline $\begin{array}{c}\text { Thermochemical } \\
\text { treatment }\end{array}$ & Parameters of thermochemical treatment & \multicolumn{2}{|c|}{ Thermal treatment } \\
\hline $\begin{array}{c}\text { Low-pressure } \\
\text { carburizing }\end{array}$ & $\begin{array}{c}\text { Temperature } 1223 \mathrm{~K} \\
\text { Time of carburizing } 90 \mathrm{~min}\end{array}$ & $\begin{array}{c}\text { Quenching in nitrogen from } \\
\text { the temperature of } 1143 \mathrm{~K}\end{array}$ & Tempering $453 \mathrm{~K} 180 \mathrm{~min}$ \\
\hline $\begin{array}{c}\text { Conventional } \\
\text { carburizing }\end{array}$ & $\begin{array}{c}\text { Temperature } 1203 \mathrm{~K} \\
\text { Time of carburizing } 120 \mathrm{~min}\end{array}$ & $\begin{array}{c}\text { Quenching in oil from the } \\
\text { temperature of } 1123 \mathrm{~K}\end{array}$ & Tempering $453 \mathrm{~K} 180 \mathrm{~min}$ \\
\hline
\end{tabular}

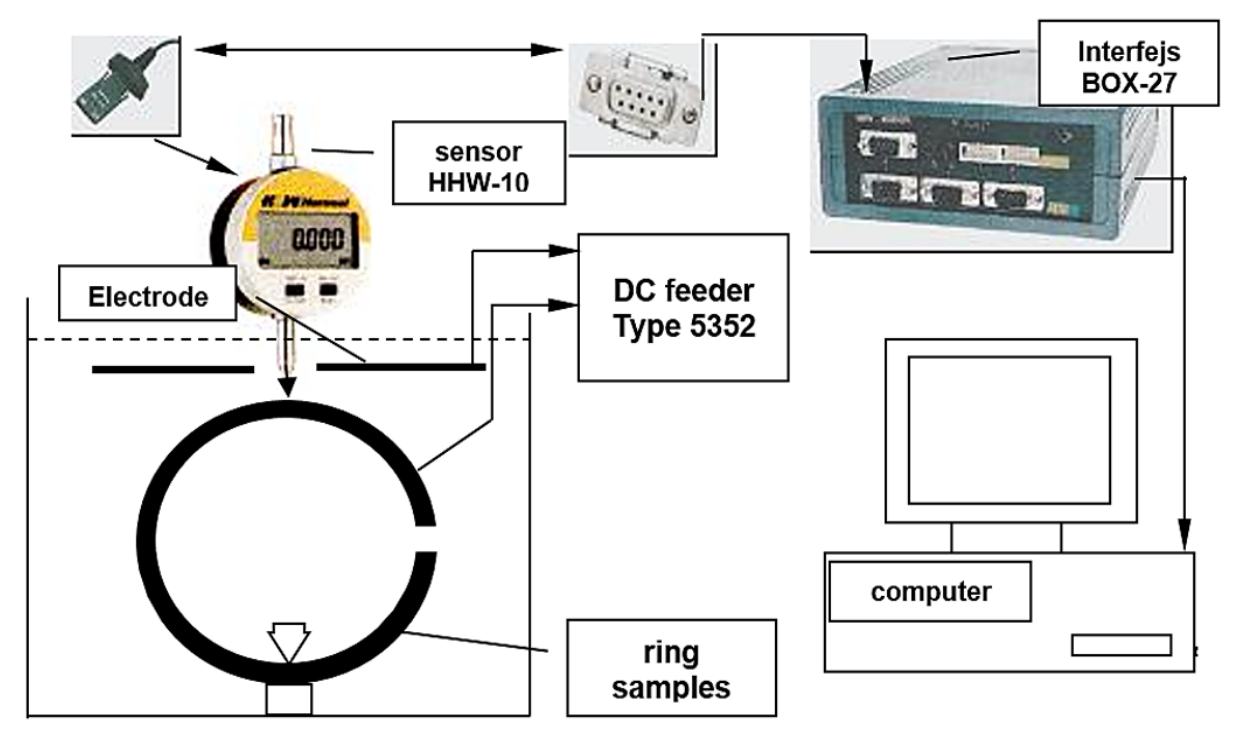

Fig. 1. The diagram of the stand for measuring residual stress by Davidenkov's method 
stand designed and constructed at the Institute of Machine Tools and Production Engineering of the Lodz University of Technology. The diagram of the stand is shown in Figure 1. The process of continuous removal of consecutive layers of the material during the measurement was done in $10 \%$ solution of $\mathrm{HNO}_{3}$, supported by direct current and forced flow of the electrolyte through the stirrer. The current density during the process of electrochemical material removal ranged from 0.3 to $0.4 \mathrm{~A} / \mathrm{cm}^{2}$. Electrochemical etching was conducted with a type 5352 type direct current feeder with voltage of 0 to $20 \mathrm{~V}$ and current regulated between 0 and $5 \mathrm{~A}$. The electrolyte temperature was controlled on a continuous basis during the electrochemical etching and the process was discontinued when the temperature increased by $2 \mathrm{~K}$. This ensured that the material would be removed in a uniform manner. HHW measuring sensors with the pressure of $1.47 \mathrm{~N}$ were used at the measuring stand. The change of a ring sample bending as a result of a change of its thickness during material removal did not exceed $0.1 \mu \mathrm{m}$ (it did not exceed the size of the elementary section of the sensor).

\section{MEASUREMENT RESULTS FOR RESIDUAL STRESS}

Figure 2 shows the results - an average of 3 measurements of residual stress in samples following the process of carburizing (except the sample after the material removal treatment). According to it, the residual stress on the surface of samples after low-pressure carburizing is -703

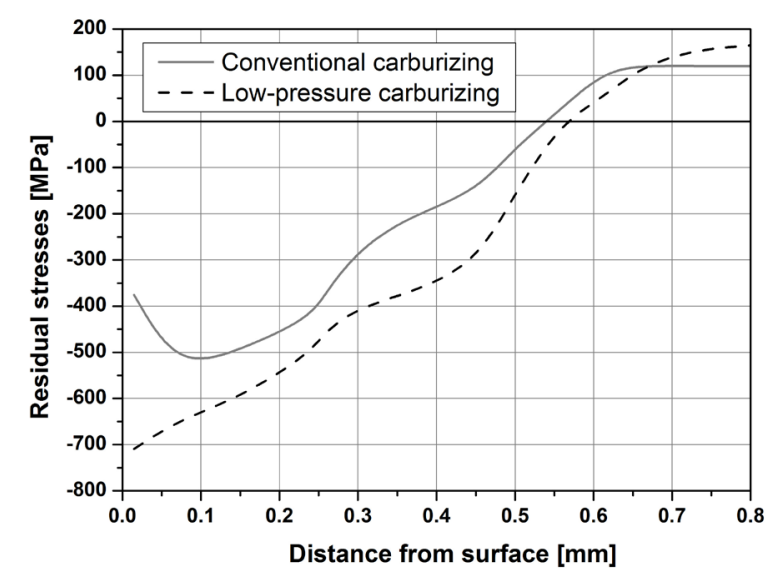

Fig. 2. Distribution of residual stress following thermochemical treatment: low-pressure and conventional carburizing
MPa. The stress decreased monotonically with the distance from the surface, reaching zero at the depth of approx. $0.56 \mathrm{~mm}$. Residual stress in samples after conventional carburizing changed differently as a function of depth. Near the surface, it was $-376 \mathrm{MPa}$ and then, at the depth of approx. $50 \mu \mathrm{m}$, the stress reached its minimum (the greatest compressive stress) of approx. $-550 \mathrm{MPa}$. Subsequently, the stress increases to reach zero at the depth of approx. $0.54 \mathrm{~mm}$ - similarly as in samples after low-pressure carburization. The nature of changes of residual stress near the surface is caused by adverse changes in the surface layer of the items after traditional carburization, i.e. decarburization and oxidation of the surface during the thermochemical treatment.

Figures 3 and 4 show a comparison of residual stress distributions for samples after low-pressure carburizing followed by grinding with a CBN grinding wheel (Fig. 3) and an aloxite grinding wheel (Fig. 4). It also shows the effect of the type of cutting fluid used in the treatment on the stress distribution in the surface layer.

Figure 3 shows that the use of a CBN grinding wheel produces beneficial compressive stress near the surface. Grinding with this grinding wheel and using oil emulsion (Fig. 3 - curve B) as the cutting fluid did not change the stress on the surface, but the nature of stress under the surface did change - probably as a result of mechanical interactions and modification of the stress resulting from removal of the machining allowance. The greatest compressive stress is present at the depth of approx. $6 \mu \mathrm{m}$ and its value is $-735 \mathrm{MPa}$. A slight change of the residual stress as observed following the grinding with a CBN grinding wheel with minimum quality lubrication (Fig. 3 - curve C). In this case, compressive stress on the surface decreased to the level of -600 MPa compared to before the treatment and approached zero or small positive (tensile) values with a distance from the surface. Despite a decrease in the compressive stress, one can accept that applying the MQL method in grinding with CBN grinding wheels gives beneficial results and it can provide an environmentally-friendly alternative to flood cooling. As expected, the worst result was achieved for dry grinding with a CBN grinding wheel (Fig. 3 - curve A). It can be noticed that with such grinding, residual stress distribution is modified by thermal effects and tempering of the sample surface. However, the level of -175 MPa can be regarded as positive with respect to the 


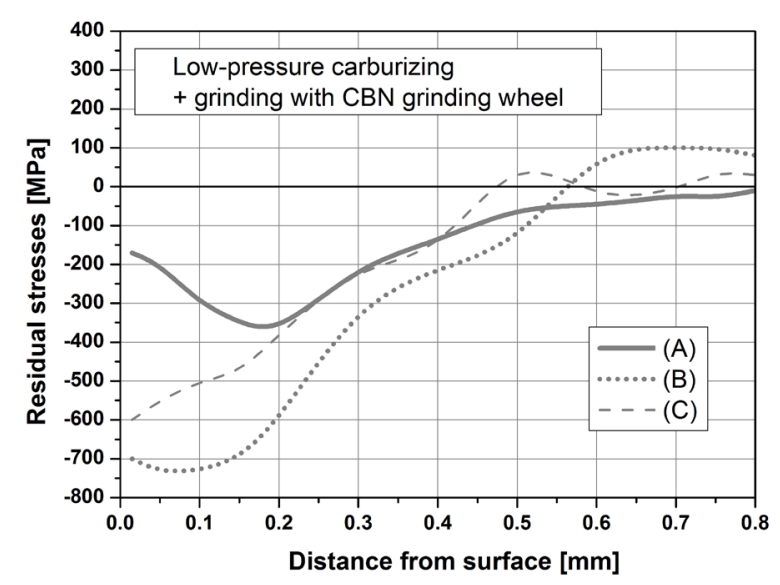

Fig. 3. Distribution of residual stress in samples following low-pressure carburization and grinding with a $\mathrm{CBN}$ grinding wheel with the use of: oil emulsion (curve B),

MQL (curve C) or with no cutting fluid (curve A)

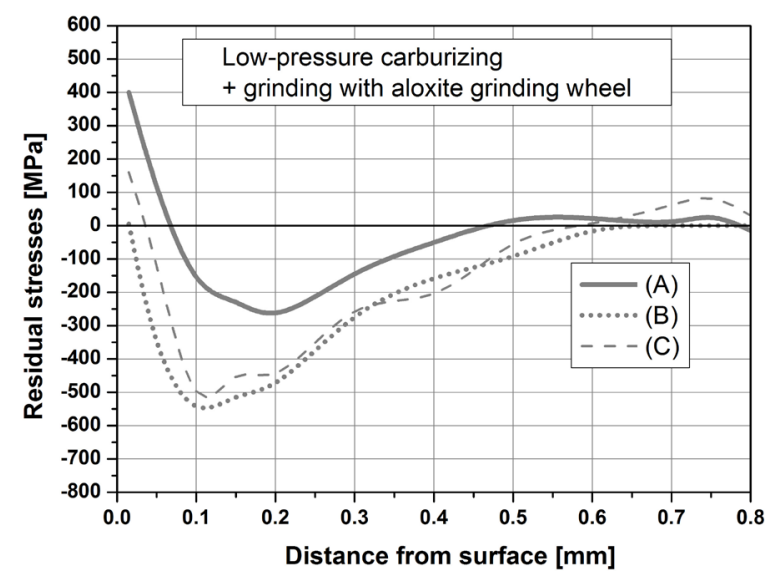

Fig. 4. Distribution of residual stress in samples following low-pressure carburization and grinding with a aloxite grinding wheel with the use of: oil emulsion (curve B), MQL (curve C) or with no cutting fluid (curve A)

utility properties of an item, although not as beneficial as in the other two cases.

Figure 4 indicates the existence of similar general relationships regarding the effect of the processing fluid on the final properties of the surface layer in the grinding process. The best results were achieved for grinding with oil emulsion supplied in the flood cooling mode (curve B in Fig. 4) and the worst - for dry grinding (curve A). Grinding with the cutting fluid supplied in the MQL mode (MQL - curve C) gave only a slightly worse result than grinding with emulsion and much better than dry grinding.

On the other hand, use of an aloxite grinding wheel alone (Fig. 4) caused deterioration of residual stress compared to the samples ground with a CBN grinding wheel (Fig. 3). This is caused by a much larger amount of heat which flows to the item, much higher temperatures of grinding, which results in adverse structural changes (among others, the process of steel tempering). Grinding with oil emulsion (but at low grinding parameters) may have resulted in surface residual stress of close to zero $(+5 \mathrm{MPa})$, which can be accepted for some machines operating at low load, but the result is much worse than for grinding with a CBN grinding wheels under the same conditions $(-705 \mathrm{MPa})$. It is also considerable deterioration of the stress compared to the samples following carburization alone, with no grinding (Fig. 2). There is no synergistic effect in this case. Applying the MQL mode with an aloxite grinding wheel resulted in a change of residual stress on the surface and its moving to the tensile stress $(+128 \mathrm{MPa})$. Although it is apparent that the effectiveness of lubrication with MQL is sufficient, the absence of a cooling effect results in an increase in the grinding temperature and, in effect, deterioration of the surface layer.

Much less beneficial distribution of stress was observed in dry grinding. Surface stress in this case reached $406 \mathrm{MPa}$ (Fig. 4 - curve A), which cannot be accepted from the point of view of using the items, especially those that operate under fatigue-causing conditions. It can be assumed that increasing the treatment parameters (treatment effectiveness) would result in deterioration of the residual stress, which is bad anyway.

Figure 5 and 6 shows a comparison of the residual stress distribution for samples carburized

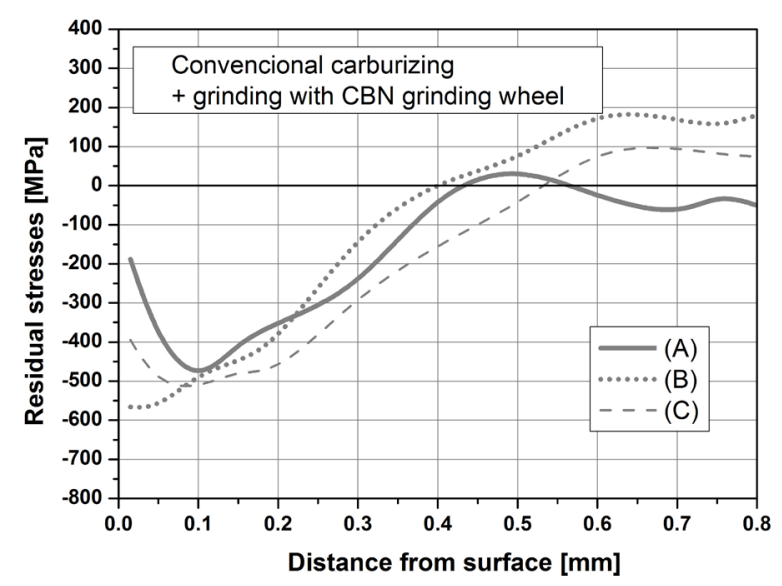

Fig. 5. Distribution of residual stress in samples following conventional carburization and grinding with a CBN grinding wheel with the use of: oil emulsion (curve B), MQL (curve C) or with no cutting fluid (curve A) 


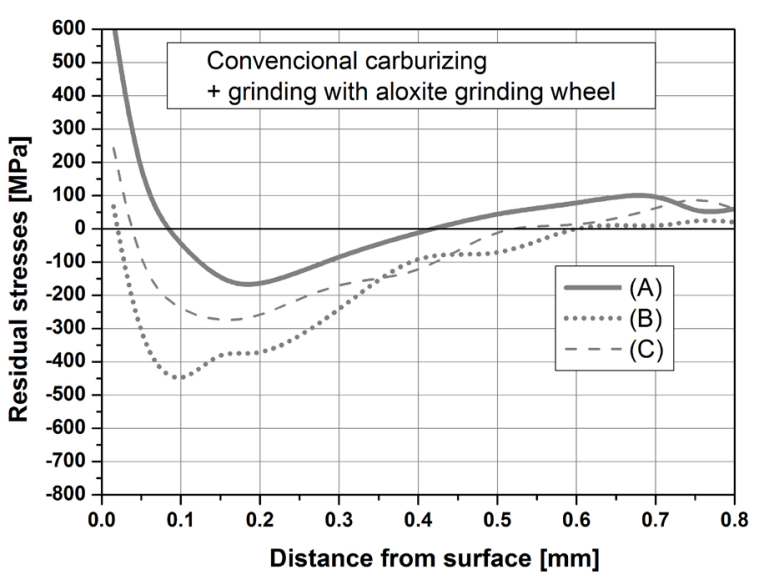

Fig. 6. Distribution of residual stress in samples following lconvencional carburization and grinding with a aloxite grinding wheel with the use of: oil emulsion (curve B), MQL (curve C) or with no cutting fluid (curve A)

by a traditional method and then treated with a CBN grinding wheel (Fig. 5) and an aloxite grinding wheel (Fig. 6). Figure 5 shows that grinding with a CBN grinding wheel had a beneficial effect on the residual stress in the surface layer of the samples. Although an adverse change of the residual stress was observed compared to the stress following the carburization process $(-184 \mathrm{MPa}$ and $-376 \mathrm{MPa}$, respectively), but this is still beneficial compressive stress.

Like for samples after low-pressure carburizing, grinding with oil emulsion as cutting fluid improved residual stress on the surface. On the other hand, grinding with MQL produced the distribution of residual stress that is close to that measured for the sample before grinding. In both these cases a synergistic effect of applying the thermochemical and material removal treatment on the properties of the surface layer is observed.

However, no such effect was achieved when a sample was ground with an aloxite grinding wheel (Fig. 6). Residual stress was found to deteriorate considerably near the surface after treatment. Compared to the stress after the thermochemical treatment $(-376 \mathrm{MPa})$, the stress after grinding with emulsion increased to +67 $\mathrm{MPa}$, after grinding with MQL it increased to $+243 \mathrm{MPa}$, and it reached a very high value of $+600 \mathrm{MPa}$ following dry grinding. These values should not be accepted in heavy duty machine parts. This indicates that the treatment efficiency cannot be improved when grinding is done with an aloxite grinding wheel.

\section{CONCLUSIONS}

The measurements of the distribution of residual stress in the surface layer of samples after carburization and ground under different condition (different grinding wheels and different methods of cutting fluid supply) lead one to the following conclusions:

- better results in regard to the residual stress level are achieved after low-pressure carburization than after traditional carburization. However, both these methods of thermochemical treatment provide a beneficial distribution of residual stress with high residual stress near the surface,

- a synergistic effect regarding residual stress resulting from a combination of thermochemical treatment and grinding can be achieved only when grinding is done with a CBN grinding wheel. Such capabilities are not offered by aloxite grinding wheels,

- the best effects of grinding with respect to the residual stress were achieved with flood cooling with oil emulsion. However, supplying cutting fluid in the MQL mode can also provide beneficial effect, especially when CBN grinding wheels are used, but it requires precise selection of the grinding conditions,

- the synergistic effect can be boosted but this requires further studies aimed at optimisation of machining conditions in order to increase the machining efficiency (which must be possible), while at the same time retaining the desired properties of the surface layer.

\section{Acknowledgements}

This work was financially supported by the Ministry of Science and Higher Education of Poland under project no. N503 013 31/1839.

\section{REFERENCES}

1. Balart M.J., Bouzina A., Edwards L., Fitzpatrick M.E. The onset of tensile residual stresses in grinding of hardened steels. Materials Science and Engineering: A, 367, 2004, 132-142.

2. Barczak L.M., Batako A.D.L., Morgan M.N. A study of plane surface grinding under minimum quantity lubrication (MQL) conditions. International Journal of Machine Tools and Manufacture, 50, 2010, 977-985. 
3. Caggiano A., Teti A. CBN grinding performance improvement in aircraft engine components manufacture. Procedia CIRP, 9, 2013,109-114.

4. Dybowski K., Sawicki J., Kula P., Januszewicz B., Atraszkiewicz R., Lipa S. The effect of the quenching method on the deformations size of gear wheels after vacuum carburizing. Archives of Metallurgy and Materials, 61 (2B), 2016, 1057-1062.

5. Gawroński Z., Kruszyński B., Kula P. Synergistic effects of thermo-chemical treatment and super abrasive grinding in gears' manufacturing. Journal of Materials Processing Technology, 159, 2005, 249-256.

6. Gawroński Z., Malasiński A., Sawicki J. Elimination of galvanic copper plating process used in hardening of conventionally carburized gear wheels. International Journal of Automotive Technology, 11(1), 2010, 127-131.

7. Gawroński Z., Sawicki J. Technological surface layer selection for small module pitches of gear wheels working under cyclic contact loads. Materials Science Forum, 513, 2006, 69-74.

8. Gräfen W., Edenhofer B. New developments in thermo-chemical diffusion processes. Surface \& Coatings Technology, 200, 2005,1830-1836.

9. Gräfen W., Hornung M., Irretier O., Rink M. Applications of low-pressure carburizing with high temperatures $\left(1000^{\circ} \mathrm{C}\right.$ to $\left.1050^{\circ} \mathrm{C}\right)$ in industrial practice. Haerterei-Technische Mitteilungen, 62 (3), 2007, 97-102.

10. Grum J. A review of the influence of grinding conditions on resulting residual stresses after induction surface hardening and grinding. Journal of Materials Processing Technology, 114 (3), 2001, 212-126.

11. Haifa S., Hédi H. Analysis of measured and predicted residual stresses induced by finish cylindrical grinding of high speed steel with CBN wheel. Procedia CIRP, 3, 2015, 381-386.

12. Karabelchtchikova O., Rivero I.V. Variability of residual stresses and superposition effect in multipass grinding of high-carbon high-chromium steel. Journal of Materials Engineering and Performance, 14, 2005, 50-60.

13. Kula P., Olejnik J., Kowalewski J. New vacuum carburizing technology. Heat Treating Progress, 1, 2001, 57-60.

14. Kula P., Olejnik J. Some technological aspects of vacuum carburizing. Proc. of the $12^{\text {th }}$ International Federation of Heat Treatment and Surface Engineering Congress, Melbourne, 2000, 3, 195-200.

15. Mittemeijer E.J., Somers M.A.J. (Eds.). Thermochemical Surface Engineering of Steels. Woodhead Publishing, 2015.

16. Monici R.D., Bianchi E.C., Catai R.E., Aguiar P.R. Analysis of the different forms of application and types of cutting fluid used in plunge cylindrical grinding using conventional and superabrasive CBN grinding wheels. International Journal of Machine Tools and Manufacture, 46, 2006, 122-131.

17. Preisser F., Seeman N.,. Zenker W.R. Vacuum Carburizing with High Pressure Gas Quenching - The Application. Proc. of the $1^{\text {st }}$ International Automotive Heat Treating Conference, Puerto Vallarta, Mexico, 1998, 135-147.

18. Sawicki J., Górecki M., Kaczmarek Ł., Gawroński Z., Dybowski K., Pietrasik R., Pawlak W. Increasing the durability of pressure dies by modern surface treatment methods. Chiang Mai Journal of Science, 40 (5), 2013, 886-897.

19. Xiao K.Q., Zhang L.C. The effect of compressed cold air and vegetable oil on the subsurface residual stress of ground tool steel. Journal of Materials Processing Technology, 178, 2006, 9-13.

20. Yao C., Wang T., Ren J.X., Xiao W. A comparative study of residual stress and affected layer in Aermet100 steel grinding with alumina and cBN wheels. The International Journal of Advanced Manufacturing Technology, 74 (1-4), 2014, 125-137. 